\title{
MALE AGGRESSION AND FEMALE EGG SIZE IN A MATE-GUARDING AMBUSH BUG: ARE THEY RELATED?*
}

\author{
By G. N. Dodson and L. D. Marshall \\ Biology Department, University of New Mexico, \\ Albuquerque, NM 87131
}

\section{INTRODUCTION}

The term "mate guarding" implies some form of active defense of a mate by the guarding individual. We previously described aspects of the mating system of Phymata fasciata (Hemiptera: Phymatidae) including the first report of mate guarding for this family (Dodson and Marshall 1984). In the present report male P. fasciata aggressive behavior is described and found to be in accordance with the expectations of mate guarding. In addition, we relate female size to egg size and discuss how this relationship may play a role in the evolution of guarding behavior.

\section{Methods}

Ambush bugs were observed on prairie sunflower (Helianthus petiolaris) in north central New Mexico. Because of low bug densities (see Dodson and Marshall 1984), encounters between single males and males guarding females were infrequent. Three naturally-occurring, guarding male:single male interactions were observed in 1982. In addition, 13 interactions were "manipulated" in the field to corroborate the accuracy of our natural observations. Manipulations involved transferring a single male to a flower already occupied by a mating pair. The transferred individual was placed as far from the pair as possible and then observed until it approached the pair or left the plant. Although there were some minor variations, three basic components of male:male interactions (see below) were the same for natural and manipulated cases. Most of the behaviors described here were also performed by bugs kept on plants in the lab.

*Manuscript received by' the editor May' 18, 1984. 
Assuming egg shape to approach that of a cylinder, we estimated volume of all chorionated eggs (EV) of 21 P. fasciata females using length and width as measured with an ocular micrometer.

\section{RESUlts AND Discussion}

When not actually copulating with a female, males rode in an amplexed position on the female dorso. Approach by a second male initiated a series of actions (Table 1). There were three components to these male interactions: orientation by the guarding male towards the intruder; stridulation by the guarding male; and an aggressive or nonaggressive action associated with contact by the intruder. Guarding males oriented towards intruders by rotating their whole body atop the female. Stridulation, audible to us at close range, involved scraping the beak back and forth across a file on the sternum. Often the guarding male began stridulating immediately upon approach by the intruder and occasionally continued even after the intruder's departure.

Contact by the intruder resulted in one of three behaviors by guarding males. Guarding males were either 1) passive (i.e., held their same position on the female whatever the intruder did) 2) repositioned themselves so as to have their bodies always between the female and the intruding male, or 3 ) physically attacked the intruder. Attacks involved the use of the raptorial fore legs and were sometimes quite vigorous. We saw males grasp an intruder's antenna for long periods and in one natural occurrence a guarder literally lifted his opponent off the substrate. No injuries were known to have resulted from this aggression, but individuals were seen with excised antennae and tarsae.

Only one displacement of a guarding male was seen in the field and it was short-lived. After being maneuvered out of the amplexed position by an intruder, the original male immediately climbed on top of the pair and began shaking vigorously back and forth. This action eventually resulted in both males toppling to the ground, and then moving further from the female's position. On two occasions in the laboratory similar separations of interactant males from females were observed. These apparently resulted from intruder males rocking vigorously while on top of paired males.

In summary, mate guarding in $P$. fasciata is active and can be highly aggressive. It is also time-intensive. Typically, pairs already 


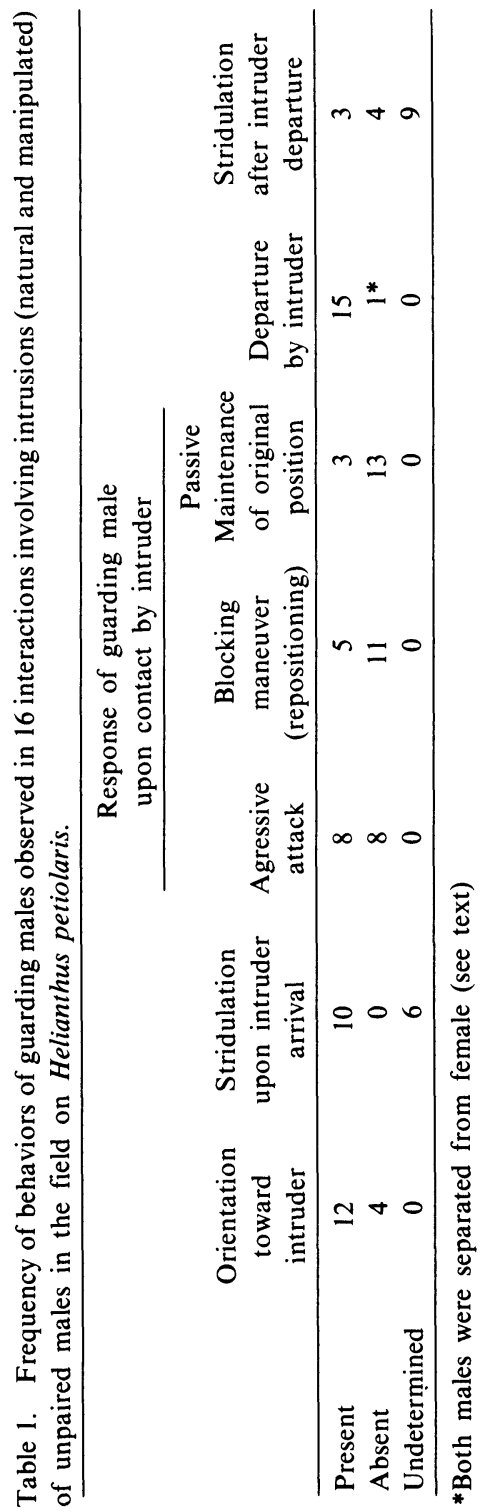


in amplexus upon our arrival in the field were still together several hours later when we departed. Pairs on flowers in the laboratory stayed together overnight. We found that these males were guarding females both prior to and following copulation (Dodson and Marshall 1984).

Presumably time spent with one female, particularly after copulation has taken place, decreases a male's opportunities for copulations with additional females. Why, then, might males be employing this guarding tactic? One possible answer is that the low population densities favor males that, upon finding a female, remain with her and actively repel other males. If such an attempt to monopolize a potential mate increased the chance of successfully copulating with her, precopulatory guarding might be a better tactic than spending this time searching for other females. This, however, seems an unlikely explanation for postcopulatory mate guarding. Parker (1970) argued persuasively that postcopulatory defense of a mate (preventing other males access to her) is an evolved strategy to counter sperm competition from potential, subsequent male mates. Although nothing is known regarding sperm precedence in ambush bugs specifically, most evidence for insects shows an insemination advantage for the last male to mate (Walker 1980).

We feel there is another factor that may be important to our understanding of mate guarding in these ambush bugs (and perhaps in other insects). This factor is male preference for particular females. At one of our study sites, males were paired with females that were heavier than females without males (Dodson and Marshall 1984). These paired females also had more eggs than single females. The apparently superior fecundity of these females seemed to us to be a potential fitness gain for males. To further investigate the possible adaptiveness of selective pairing by males we looked at egg size within females. We had previously determined the wet weight (WW), pronotal width (PW) and femur length (FL) of these same females. All 3 measurements were significantly correlated with egg volume (BW: $r=.60, p=.003 ; P W: r=.61, p=.003 ; F L: r=$ $.62, \mathrm{p}=.002)$. The 3 measurements are so highly correlated with each other, the residual variation examined by partial correlations was found to be negligible $\left(\mathrm{r}_{\mathrm{EV} \mathrm{FL}} \cdot \mathrm{wW} \mathrm{PW}=.04, \mathrm{p}=.84 ; \mathrm{r}_{\mathrm{EV} \mathrm{PW}} \cdot \mathrm{wW} \mathrm{FL}\right.$ $\left.=.24, \mathrm{p}=.31 ; \mathrm{r}_{\mathrm{EV} \mathrm{wW}} \cdot \mathrm{PW} \mathrm{FL}=.27, \mathrm{p}=.25\right)$. Therefore, all 3 variables are approximately equivalent predictors of egg volume. We believe, 
as Johnson (1982) suggested, that this could potentially provide males with a basis for discriminating the most reproductively fit females. Males capable of assessing a cue to female fitness could "decide" whether to remain with a particular female or search for another. This would explain our findings of large females most often in pairs. Such a tactic could be even more feasible in insect populations which occur in high densities. The resulting high encounter rates would mean less time spent searching for more suitable mates.

This hypothesis assumes that larger eggs enhance the success of resultant offspring (e.g., through increased nutrient provisions or greater competitive ability of larvae). Such advantages are controversial, but the rather limited data do yield some support. Relationships between egg size and offspring success in insects have been addressed by Capinera (1979 and references therein), Richards and Myers (1980) and Barbosa, et al. (1981).

Discrimination of mates by males has been shown in several species in which males are contributing relatively large amounts of paternal care or other benefits (for insect examples see Thornhill and Alcock 1983). Perhaps more significant for this discussion are the findings of mate discrimination by males of noninvesting species (Loiselle; 1982; Verrel 1982; Hatziolos, M. E. and R. L. Caldwell 1983; references in Thornhill and Alcock 1983; Johnson and Hubbell, unpublished). Although some of the latter examples are laboratory experiments, the fact that the apparently adaptive behavior is exhibited suggests that selection under natural circumstances must be occurring at significant levels.

Several recent papers have reported overrepresentations of larger females within mating populations of insects. Such biases, based on either size or weight, have been found in beetles (McCauley and Wade 1978, Johnson 1982 and McLain 1982), pierid butterflies (Marshall 1982), ambush bugs (Dodson and Marshall 1984) and tephritid flies (Dodson, submitted). It would be interesting to determine the relationship between female body size and egg size in all such species in light of a male mate discrimination hypothesis.

McCauley and Wade (1978) showed that mating male and female soldier beetles, Chaulignathus pennsy/vanicus, were heavier than nonmating males and females based on dry weights. They considered dry weight to be an index of body size and suggested larger 
females could be preferentially mating with larger (and presumably more fit) males by physically resisting mating attempts by all males and escaping the smaller ones. They further postulated that larger females might be "somewhat more receptive than small females". However, except for the suggestion that receptivity might be related to egg development, they did not account for the paucity of small females in the mating population. Woodhead (1981) offered what appeared to be a more parsimonious explanation. She found that mating females had larger eggs than "rejecting" females and proposed that heavier female soldier beetles were more often found mating because they were more reproductively mature and therefore more receptive to mating. Woodhead (1981) did not discuss her choice of eggs for measurement. She did state that soldier beetles "mature eggs in groups" and so we assume that all primary oocytes were measured, including many not yet fully-yolked. Even if this were the case, however, her measurements are also consistent with the hypothesis that females differ in ultimate egg size and not just developmental stage.

In many insects, oocytes are in various stages of development within the ovaries throughout most of a female's adult life. This makes comparative measures of all eggs virtually impossible because of the miniscule size of the youngest oocytes. For valid comparisons between females, age classes of eggs must be delineated. Typically, fully-yolked eggs are chosen because they are easily defined, relatively easy to distinguish (although not always), and supposedly will not get any larger. We avoided this problem by measuring only chorionated eggs, i.e., eggs that are fully grown with their "shells" encasing them. Thus, we have demonstrated variation in egg sizes between females which are independent of sexual maturity and apparently dependent on female size.

In summary, we have shown that $P$. fasciata males, when paired with females, aggressively fend off intruding males and that larger females produce larger eggs. Previous work (Dodson and Marshall 1984) revealed that males were more often paired with larger rather than small females in a natural population. All of these factors are consistent with the hypothesis that given some choice, males will preferentially guard mates which provide a higher reproductive potential. 


\section{RIFERENC'S}

Barbosa, P., W. Crankshaw and J. A. Greinhiatt. 1981. Influence of food quantity and quality on polymorphic dispersal behaviors in the gypsy moth, Lymantria dispar. Can. J. Zool. 59: 293-296.

Capinera, J. L. 1979. Qualitative variation in plants and insects: effect of propagule size on ecological plasticity. Am. Nat. 114 (3): 350-361.

Dodson, G. N. And L. D. Marshal.t. 1984. Mating patterns in an ambush bug. Phımata fasciata. (Phymatidae). Amer. Midl. Nat., in press.

Hatziolos, M. E. and R. L. Caldowhll. 1983. Role reversal in courtship in the stomatopod Pseudosquilla ciliata (Crustacea). Anim. Behav. 31: 1077 - 1087.

Jomsson, J. K. 1982. Sexual selection in a brentid weevil. Evolution 36 (2): $251-262$.

LoISELL..., P. V. 1932. Male spawning-partner preference in an arean-breeding teleost Cyprinodon macularius californiensis Girard (Atherinomorpha: Cyprinoclontidae). Am. Nat. 120 (6): 721.732.

Marsiati., L. D. 1982. Male courtship persistence in Colias philodice and C. eurytheme (Lepidoptera: Pieridae). J. Kans. Entomol. Soc. 55 (4): 729 - 736.

MCCAnley, D. E. AND M. J. WADE. 1978. Female choice and the mating structure of a natural population of the soldier beetle. Chauliognathus pennsy/ranicus. Evolution 32: $771-775$.

McLain, D. K. 1982. Density dependent sexual selection and phenotypic assortative mating in natural populations of the soldier beetle. Chauliognathus pennsy/vanicus. Evolution 36 (6): $1227-1235$.

Richards, L. J. AND J. H. MYers. 1980. Maternal influences on size and emergence time of the cinnabar moth. Can. J. Zool. 58: 1452 - 1457.

Thornili., R. AND J. Aicoc'K. 1983. The Evolution of Insect Mating Systems. Harvard University Press, Cambridge, MA. 547 pp.

Verrei. P. A. 1982. Male newts prefer large females as mates. Anim. Behav. 30: $1254-1255$.

WoodneAd, A. P. 1981. Female dry weight and female choice in Chauliognathus pennsy/vanicus. Evolution 35: 192-193. 

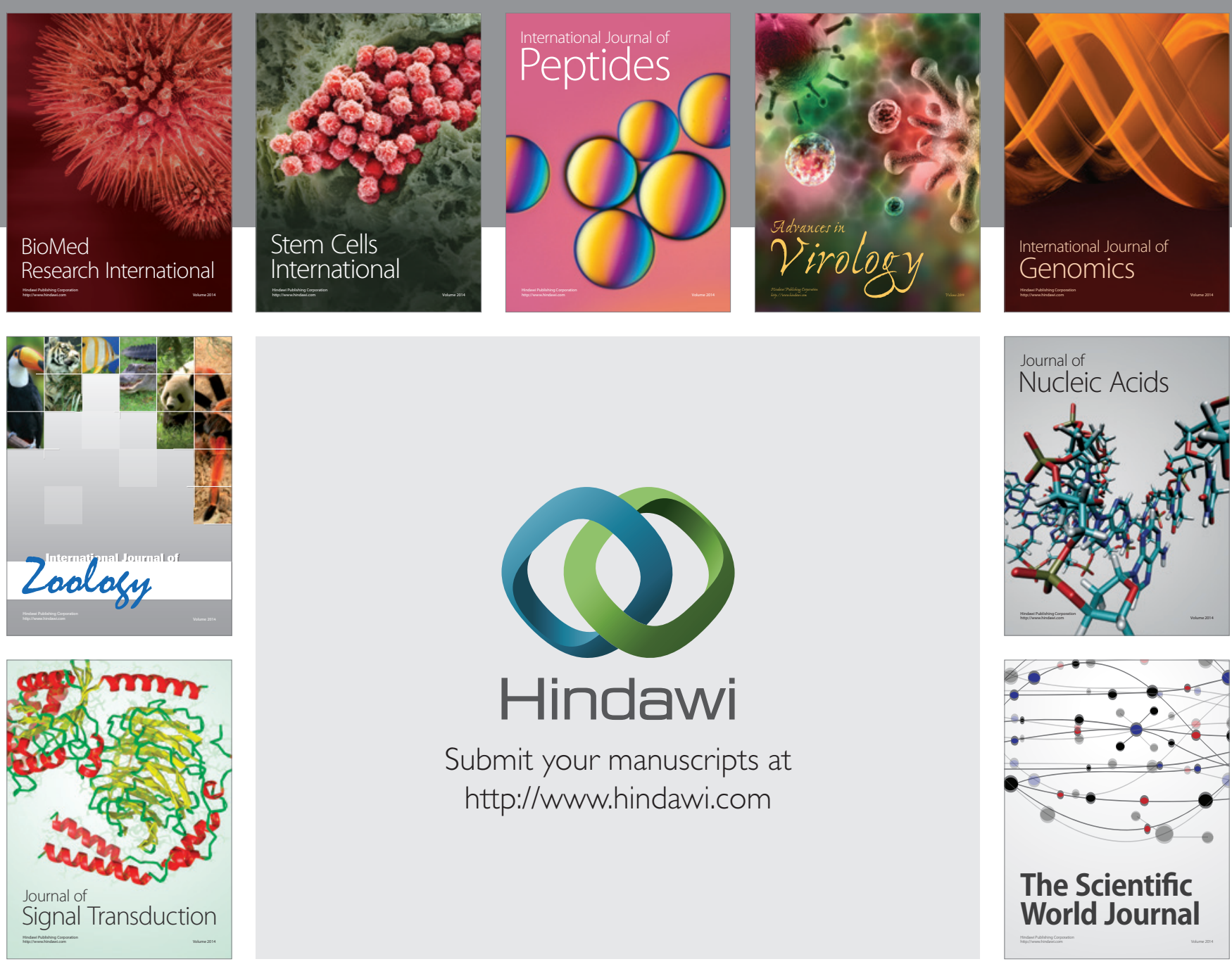

Submit your manuscripts at

http://www.hindawi.com
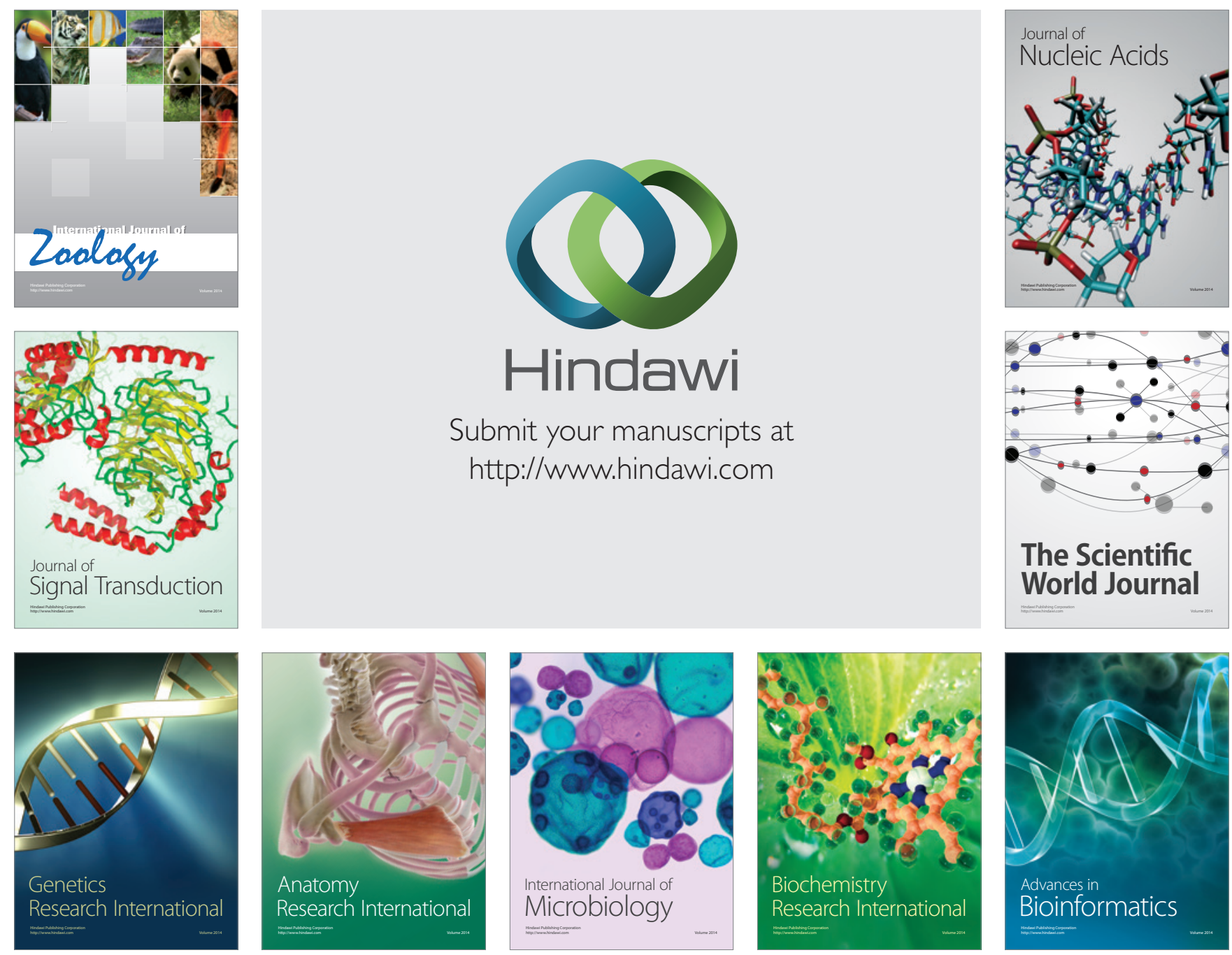

The Scientific World Journal
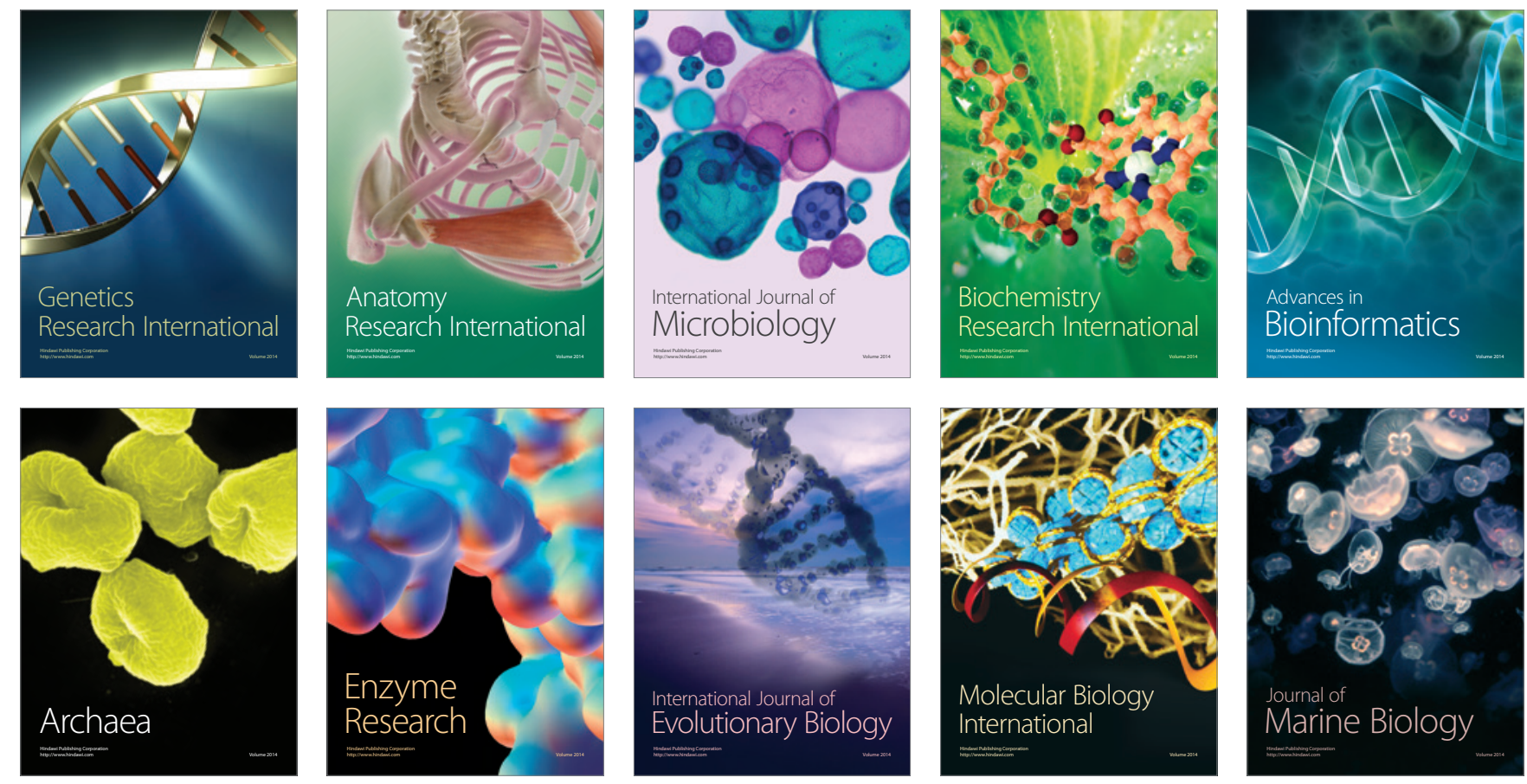